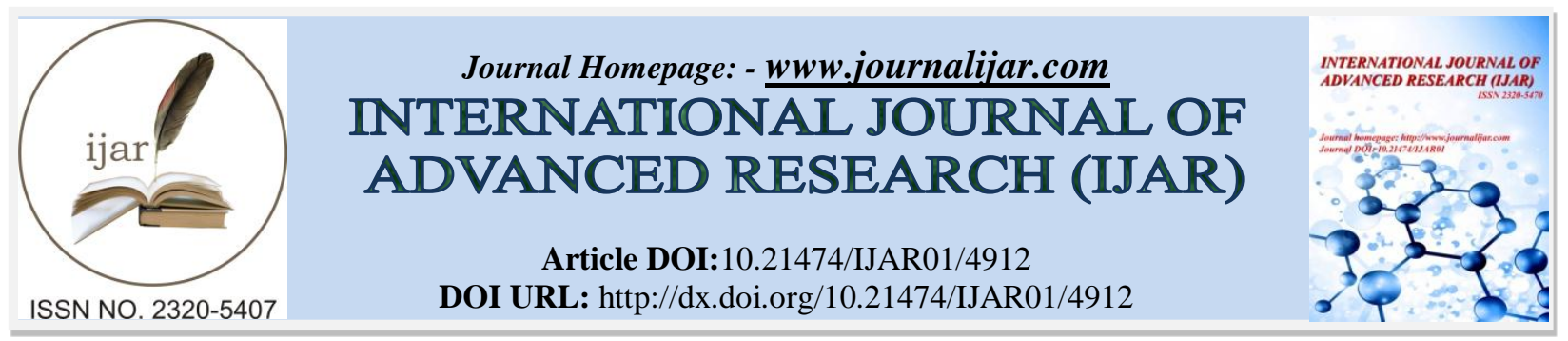

RESEARCH ARTICLE

\title{
CLOZAPINE INDUCED CONSTIPATION: A CASE REPORT.
}

\author{
Ali Mahmood Khan ${ }^{1}$, Javeria Sahib Din ${ }^{1}$, Faiza Farooq ${ }^{1}$, Ashraf Farooq Arain ${ }^{2}$, Mohammad Mustafa \\ Ahmed $^{2}$, Shanila Shagufta ${ }^{1}$ and Abdul Mohit ${ }^{3}$. \\ 1. Kings County Hospital Center, NY, USA. \\ 2. Ziauddin University, Karachi, Pakistan. \\ 3. Behavioral Health, Kings County Hospital Center, NY, USA.
}

\section{Manuscript Info}

Manuscript History

Received: 21 May 2017

Final Accepted: 23 June 2017

Published: July 2017

\section{Abstract}

This is a case of a 50 year old male with multiple psychiatric admissions and medication non-adherence with past psychiatric diagnosis of schizoaffective disorder. The patient presented with being disorganized and psychotic, aggressive towards family members and having side effects to medication which were agranulocytosis crisis, drooling and akinesia. Patient was admitted to the unit from outpatient department and was started on Clozapine 100mg per-oral in the morning and $300 \mathrm{mg}$ per-oral at bedtime, Depakote 1000mg peroral in the morning and $1500 \mathrm{mg}$ per-oral bedtime and Prolxin $5 \mathrm{mg}$ per-oral BID.Over the course of time the patient developed constipation due to clozapine, which led to him having small bowel obstruction and eventually exploratory laparotomy. Patient had no previous history of abdominal surgery.

Copy Right, IJAR, 2017,. All rights reserved.

\section{Introduction:-}

This research is being conducted to establish the role of clozapine in inducing constipation. Previous researches state that clozapine induced constipation is a side effect frequently overlooked but may prove to be life threatening [1]. The basis of this research is to find out the relationship between clozapine and constipation.

\section{Case Presentation:-}

This patient is a 50 year old male, single, unemployed, domiciled with a diagnosis of schizoaffective disorder and multiple past admission was initially admitted on the unit on the 11/23/16. Patient was referred from the out-patient, because the patient was being aggressive towards family members and having side effects to medication which were agranulocytosis crisis, drooling and akinesia. Patient was disorganized and psychotic during initial. admission.Initially on the floor, he was aggressive at times, sexually pre-occupied and claiming that he is married to all women, impregnated them and has a lot of children around. He called himself "King James", and "Sky Love." At times he would start yelling at the staff and cursing them, and a few minutes after would apologize for his act and kept telling everyone "I love you" while crying. Additionally patient has a history of medication non-adherence. At the time of admission patient was on Clozapine $100 \mathrm{mg}$ per-oral in the morning and $300 \mathrm{mg}$ per-oral at bedtime, Depakote 1000mg per-oral in the morning and 1500mg per-oral bedtime and Prolxin 5mg per-oral BID.

In the unit he was continued on Clozapine, which led to him developing constipation which eventually led to him developing intestinal obstruction of the small bowel and was therefore transferred to the medical floor on 
11/26/16.At the time of development of small bowel obstruction his medication regimen included Fluphenazine $5 \mathrm{mg}$ morning, 10 qhs, Clozapine $100 \mathrm{mg}$ morning, 300 qhs, Depakote $1000 \mathrm{mg}$ BID.The patient went through an exploratory laparotomy secondary to small bowel obstruction, reduction of volvulus was performed, and 2 days later he was taken back to operating room for reduction of abdominal hypertension, which was successful. PostsurgeryClozapine was discontinued and his medication regimen was changed to monotherapy Prolixin. On the $12^{\text {th }}$ post-operative day he was transferred back to the psychiatry unit for continuation of his psychiatric treatment and stabilization. The patient's symptoms had not been controlled hence Prolixin with Loxapine was tried. However due to unacceptable extrapyramidal side effects patient was switched to Prolixin and Zyprexa. This combination was clinically in-effective therefore Seroquel was added. Although his psychosis were better controlled his affect was still dysregulated hence Depakote 1500mg BID was added.

After arriving to the unit he was found to be very weak with unstable gait and selectively mute. Patient appeared to be internally preoccupied and psychotic. Additionally patient stated that he tried to commit suicide when he was younger but denied any current suicidal and homicidal ideations on the unit. On mental status evaluation the patient's insight was poor; judgment was impaired; attention span was poor by interview; memory was grossly intact;intellectual functioning was intact; affect was labile.

Patienthas no history of substance abuse or intoxications, which was confirmed by a negative urine toxicology. Patient had poor social support, and has had problems with keeping relationships due to his aggression. The protective factors for the patient are his supportive sister and stable housing. On the unit, patient was counselled for medication adherence, attending groups and to learn coping skills for his aggressive behavior.

Gradually patient's behavior regressed on the unit, his thought process became more linear and his affect stabilized. He became selectively mute, stayed in his room most of the times, but did come out and participated in groups few times. Patient's bowel movement was continuously assessed by the medical and psychiatric team. Patient had some constipation but his bowel movements were recorded to be every 2-3days by the time of his discharge. Patient was offered to be re-started on Clozapine since it had good effect for him but he refused. Treatment team did not ask for court-override since his psychosis and affect symptoms were well controlled with medication regimen at the time of discharge which was Zyprexa 40mg per-oral qhs, Depakote $1500 \mathrm{mg}$ BIDper-oral and Seroquel $300 \mathrm{mg}$ per-oral in the morning and 400mg qhs per-oraland Prolxin 5mg per-oral BID. At the time of discharge he had no suicidal ideation, plan, or intent and was not an imminent danger to himself or others. Pt was discharged back to her sister's house and with follow up appointment in the out-patient.

\section{Discussion:-}

Clozapine is a tricyclic dibenzodiazepine and it is classified as an atypical antipsychotic agent, which binds to various types of Central Nervous System receptors. It is a serotonin antagonist and binds to 5 -HT $2 \mathrm{~A} / 2 \mathrm{C}$ receptor subtype. It has weak antagonism for dopamine D2 receptor as well. It is used to treat patients with treatmentresistant schizophrenia, suicidal behavior and advanced dopaminomimetic psychosis. The drug is metabolized by hepatic enzymes and has a half-life of around 8 hours. It is the only atypical antipsychotic which is better than all other antipsychotics [2]. Schizophrenia patients who do not improve with other atypical antipsychotics, show improved results by switching to Clozapine [3].

Constipation is a clinical manifestation which has different ways of presenting itself, some of the symptoms include hard stools, infrequent defecation and feeling of incomplete bowel movement. It is caused by a variety of reasons with low intake of fiber a very common one along with drugs such as antipsychotics, diuretics and calcium channel blockers, known to cause hypomotility. Stress and anxiety is also considered to be one of the factors for causing constipation.

The gut has innervations from cholinergic and serotonergic receptors (5-HT3) so Clozapine induces constipation using its strong antagonist effects on serotonin receptors (5-HT2, 5-HT3, 5-HT6, 5-HT7), leading to hypomotility [8]. Although a number of antipsychotics cause constipation, studies indicate Clozapine induced constipation is quite common and is "approximately three times more likely to occur than with other antipsychotics" [1]. Though constipation is not a serious side effect of Clozapine, reports state that if left undiagnosed and untreated, it may potentially prove to be fatal and cause death [4]. There are a number of complications due to increased gastrointestinal hypo-motility which can prove fatal [9]. Some of the complications due to gastrointestinal hypomotility include severe fecal impaction which may lead to vomiting or bowel necrosis [10]. It is difficult for 
physicians to diagnose such severe complications at times as patients with schizophrenia could have decreased sensitivity to pain [5]. The lowered sensitivity may cause the patient to not recognize the pain being caused due to the increased hypomotility [6]. Even if pain perception is normal, expression of pain is considered to be difficult for patients suffering from schizophrenia [7]. Approximately $40 \%$ of cases that were reported of severe clozapine induced gastrointestinal motility took place within a span of 4 months since treatment was initiated [9].

Patients with clozapine induced constipation should be educated about the risk of constipation and warned about usage of drugs which may elevate the risk of hypomotility [10]. Laxatives such as Senna, Docusate, lactulose or Polyethylene glycol may be used for treatment of clozapine induced constipation [9][11].

\section{Conclusion:-}

In light of previous researches, it can be said that constipation is a common side effect of clozapine but may progress to life threatening complications if left untreated. Patients should be monitored closely while being treated with clozapine to avoid the risk of constipation being left undiagnosed.

\section{References:-}

1. Shirazi A1, Stubbs B2,3, Gomez L4, Moore S5, Gaughran F6,7, Flanagan RJ8, MacCabe JH9,10, Lally J11,12. Prevalence and Predictors of Clozapine-Associated Constipation: A Systematic Review and Meta-Analysis. Int J Mol Sci. 2016 Jun 2;17(6). pii: E863. doi: 10.3390/ijms17060863.

2. Nucifora FC Jr1, Mihaljevic M2, Lee BJ3, Sawa A3. Clozapine as a Model for Antipsychotic Development. Neurotherapeutics. 2017 Jul;14(3):750-761. doi: 10.1007/s13311-017-0552-9.

3. McEvoy JP1, Lieberman JA, Stroup TS, Davis SM, Meltzer HY, Rosenheck RA, Swartz MS, Perkins DO, Keefe RS, Davis CE, Severe J, Hsiao JK; CATIE Investigators. Effectiveness of clozapine versus olanzapine, quetiapine, and risperidone in patients with chronic schizophrenia who did not respond to prior atypical antipsychotic treatment. Am J Psychiatry. 2006 Apr;163(4):600-10.

4. Levin TT1, Barrett J, Mendelowitz A. Death from clozapine-induced constipation: case report and literature review. Psychosomatics. 2002 Jan-Feb;43(1):71-3.

5. Dworkin RH: Pain insensitivity in schizophrenia: a neglected phenomenon and some implications. Schizophr Bull 1994; 20:235- 248.

6. Rosenthal SH, Porter KA, Coffey B: Pain insensitivity in schizophrenia. Case report and review of the literature. Gen Hosp Psychiatry 1990; 12:319-322

7. Bickerstaff LK, Harris SC, Leggett RS, et al: Pain insensitivity in schizophrenic patients. A surgical dilemma. Arch Surg 1988; 123:49-51

8. Perrott J. Serious gastrointestinal adverse effects of clozapine. Psychopharmacology Newsletter. 2009;1-5

9. Palmer SE, McLean RM, Ellis PM , Harrison-Woolrych M. Life-threatening clozapine-induced gastrointestinal hypomotility: an analysis of 102 cases. J Clin Psychiatry. 2008;69(5):759-68. PubMed PMID: 18452342. [Crossref]

10. Jill A. Fowler. Clozapine-induced gastrointestinal hypomotility: More than just constipation. Mental Health Clinician: November 2011, Vol. 1, No. 5, pp. 92-93.

11. Hibbard KR, Propst A, Frank DE, Wyse J . Fatalities associated with clozapine-related constipation and bowel obstruction: a literature review and two case reports.Psychosomatics. 2009;50(4):416-9. DOI: 10.1176/appi.psy.50.4.416. PubMed PMID: 19687183. [Crossref]. 